\title{
ALK inhibitors and advanced non-small cell lung cancer (Review)
}

\author{
ANTONIO ROSSI $^{1}$, PAOLO MAIONE ${ }^{1}$, PAOLA CLAUDIA SACCO ${ }^{1}$, ASSUNTA SGAMBATO ${ }^{2}$, \\ FRANCESCA CASALUCE $^{2}$, MARIANNA LUCIANA FERRARA ${ }^{2}$, GIOVANNI PALAZZOLO ${ }^{3}$, \\ FORTUNATO CIARDIELLO ${ }^{2}$ and CESARE GRIDELLI ${ }^{1}$
}

${ }^{1}$ Division of Medical Oncology, 'S.G. Moscati' Hospital, Avellino; ${ }^{2}$ Department of Clinical and Experimental Medicine, Second University of Naples, Naples; ${ }^{3}$ Division of Medical Oncology, 'ULSS 15 Cittadella', Padova, Italy

Received March 25, 2014; Accepted May 16, 2014

DOI: $10.3892 /$ ijo.2014.2475

\begin{abstract}
Treatment of unselected patients with advanced non-small cell lung cancer (NSCLC) receiving third-generation platinum-based chemotherapy has reached a plateau of effectiveness. Histology and molecular analyses are the cornerstone in the initial diagnosis of NSCLC and are key determinants to address the appropriate strategy of treatment. In non-squamous histology the combination of cisplatin plus pemetrexed or carboplatin plus paclitaxel plus bevacizumab are considered today the best regimens yielding better activity and efficacy. Epidermal growth factor receptor $(E G F R)$ tyrosine kinase inhibitors (TKIs), such as gefitinib, erlotinib or afatinib are the standard-of-care for patients with advanced NSCLC harbouring activating EGFR mutations. The identification of anaplastic lymphoma kinase $(A L K)$ rearrangements in $2-5 \%$ of NSCLC patients led to the rapid clinical development of its oral TKI, crizotinib, also targeting the proto-oncogene $M E T$ and ROS1. The results reported from the first phase III trial showed superiority of crizotinib compared with standard chemotherapy in second-line treatment of $A L K$-positive NSCLC, which was recently approved in several countries in this setting. Unfortunately, after initial activity of crizotinib, patients will ultimately develop acquired resistances within 1 or 2 years of therapy. A second generation of ALK inhibitors, such as LDK378, alectinib and AP26113 may represent a promising treatment approach: they are under investigation with very promising early results. This review discusses $A L K$ rearrangements, the clinical development and use of crizotinib, and other ALK-TKIs in advanced NSCLC.
\end{abstract}

Correspondence to: Dr Antonio Rossi, Division of Medical Oncology, 'S.G. Moscati' Hospital, Contrada Amoretta 8, I-83100 Avellino, Italy

E-mail: arossi_it@yahoo.it

Key words: ALK, brain metastases, crizotinib, HSP90 inhibitors, LDK378, NSCLC, pemetrexed, mechanisms of resistance, ROS1

\section{Contents}

1. Introduction

2. ALK gene alterations in NSCLC

3. Crizotinib clinical development

4. Crizotinib resistance

5. Therapeutic strategies to overcome crizotinib resistance

6. Special topics

7. Conclusion

\section{Introduction}

The outcome for unselected patients with advanced non-small cell lung cancer (NSCLC) remains dismal with third-generation platinum-based chemotherapy as the cornerstone of treatment. However, the more recent successful development of therapies targeting NSCLC histotype or oncogenic drivers led to survival improvements in selected populations (1).

In first-line treatment of advanced non-squamous NSCLC, cisplatin plus pemetrexed is considered the best chemotherapeutic regimen (2). Bevacizumab, a pure humanized anti-vascular endothelial growth factor (VEGF) monoclonal antibody (mAb), when combined with carboplatin plus paclitaxel, improved the survival compared with chemotherapy alone, as first-line therapy for non-squamous NSCLC patients (3). The identification of somatic mutations in the epidermal growth factor receptor $(E G F R)$ gene in a subset of patients with NSCLC led to the treatment of these patients with EGFR tyrosine kinase inhibitors (TKIs), such as gefitinib, erlotinib or afatinib. Several randomized phase III trials, addressed to this subset of patients, showed a superior response rate, prolonged progression-free survival (PFS), and improved quality of life (QoL) of EGFR-TKIs when compared with platinum-based chemotherapy. Although no overall survival (OS) advantage was demonstrated, because all the trials suffered of a high post-progression treatment cross-over which inevitably undermined the results, global OS was not observed in NSCLC before the introduction of EGFR-TKIs in the treatment of EGFR mutant patients. Unfortunately, both de novo and acquired resistance to targeted therapies limit the duration of their clinical benefit (4). 
Recently, the anaplastic lymphoma kinase $(A L K)$ gene fusion emerged as an important biomarker for selecting a further subgroup of NSCLC patients to be treated with corresponding inhibitors. The state-of-the-art of this approach and its future developments are discussed here.

\section{ALK gene alterations in NSCLC}

$A L K$ is a transmembrane receptor tyrosine kinase member of the insulin receptor superfamily. Chromosomal rearrangement of the $A L K$ gene and its activation, generally takes place through the position of one of several different 5 fusion partners and their associated promoter region upstream of the kinase domain of $A L K$, inducing its transcription and protein expression. Approximately $2-5 \%$ of patients with NSCLC have tumours with an inversion in the short arm of chromosome 2 [inv (2)(p21p23)] which results in the fusion of exons 1-13 of the echinoderm microtubule-associated protein-like 4 (EML4) gene with exons 20-29 of the $A L K$ gene, leading to the production of an EML4-ALK fusion tyrosine kinase which is involved in cell proliferation, differentiation and anti-apoptosis (5). Thus, the EML4-ALK protein contains the intracellular catalytic domain of ALK and the aminoterminal half of EML4 including the hydrophobic echinoderm microtubule-associated protein-like protein (HELP), which is critical for dimerization of EML4-ALK, resulting in an aberrant constitutive activity of downstream signalling such as Akt, STAT3, and extracellular signal regulated kinase 1 and 2 (ERK1/2) (6-8). Other less-frequent fusion partners of $A L K$, such as TFG and KIF5B, have since been reported $(9,10)$. A higher probability to detect $A L K$ translocations seems to be associated with specific clinical NSCLC patients characteristics including never or light smoking history, young age and adenocarcinoma histology with signet rings (11-13).

$A L K$ translocations typically occur independently of $E G F R$ or $K R A S$ mutations, although they are not mutually exclusive, and predict for a poor response to EGFR-TKIs, less responsiveness to platinum-based chemotherapy, and a lower OS in patients with advanced NSCLC (13-16). Recently, thousands of NSCLC patients were analyzed for biomarkers characteristics by two platforms: the French and the Lung Cancer Mutation Consortium. In both series, some $A L K$-positive specimens were found positive also for either an $E G F R$ or $K R A S$ mutation $(17,18)$. In a phase III randomized trial comparing erlotinib versus platinum-based chemotherapy as first-line treatment of patients with advanced NSCLC harbouring activating EGFR mutations, $15.8 \%$ of patients were found to have also the $E M L 4-A L K$ translocation. Despite this, no negative impact on outcome in terms of PFS, primary objective of the trial, was found, with erlotinib scoring statistically better than chemotherapy $(19,20)$. Overall, patients with activating $E G F R$ mutations and previous objective response to EGFR-TKIs, should not be excluded from $A L K$ screening even though a difference to EGFR-TKI susceptibility was not observed in the EURTAC trial (20).

ALK translocation diagnostic tools. The major recommendations, by the International Association for the Study of Lung Cancer (IASLC), are to use testing for $A L K$ fusions to guide patient selection for therapy with an ALK inhibitor in all patients with advanced-stage adenocarcinoma, regardless of sex, race, smoking history or other clinical risk factors (21). Of importance is the method which should be used for $A L K$ testing. To date, the fluorescent in situ hybridization (FISH) assay using dual-labelled break-apart probes for selecting patients for ALK-TKI therapy is the diagnostic gold standard approved also by FDA (21). This methodology was used in the initial studies that demonstrated improved clinical response of patients with $A L K$-rearranged tumours to treatment with crizotinib, an ALK-TKI $(12,13,22)$. As reported by this test, the indicative cut-off of an ALK rearrangement is the observation of $>15 \%$ split nuclei (22). ALK immunohistochemistry (IHC) being an easier and cheaper diagnostic tool is currently under investigation to be considered as a pre-screening methodology to select specimens for ALK FISH testing (21). Until now, many reports demonstrated a strong correlation between ALK IHC expression and ALK FISH positivity or negativity (23-27); however, further confirmation is needed to definitely include the ALK IHC detection as the initial step in the algorithm for clinical ALK testing in NSCLC. Reverse transcriptase polymerase chain reaction (RT-PCR) is not currently recommended as a first-line diagnostic method for determining $A L K$ fusion status. A higher failure rate of a ribonucleic acid (RNA)-based assay in routine formalin fixed paraffin-embedded (FFPE) pathology material might affect sensitivity, with the risk of false-negatives, due to variability in the EML4-ALK fusion structure and to the existence of other $A L K$ fusion partners (21).

\section{Crizotinib clinical development}

Crizotinib (PF-02341066) is a first-in-class oral adenosine triphosphate (ATP)-competitive selective inhibitor of the ALK and MET tyrosine kinases with additional ROS1 and RON kinase inhibitory activity $(28,29)$. In 2006 began the first-in-man phase I crizotinib study with a dose escalation undertaken in 37 patients with advanced solid tumours. The escalating doses of crizotinib were from $50 \mathrm{mg}$ once daily to $300 \mathrm{mg}$ twice daily, using a standard dose-escalation design. Dose-limiting fatigue in the cohort receiving $300 \mathrm{mg}$ twice daily led to the establishment of a regimen of $250 \mathrm{mg}$ twice daily in a 28 -day cycle as the recommended phase II study dose. This part of the trial was followed by protocol-defined patient prescreening for evidence of $A L K$ or $M E T$ activation in specific tumour types. The discovery of $A L K$ gene rearrangements in NSCLC and the promising results reported in two patients with $A L K$-positive NSCLC led, in 2008, to expand the cohort of $A L K$-positive NSCLC to enrol $(30,31)$. The objective response rate from the first 19 evaluable patients with $A L K$-positive NSCLC and who had been heavily pretreated was $53 \%$ (30). These interesting data were subsequently confirmed in the first 82 patients in which an objective response rate of $57 \%$ was reached with a $33 \%$ of stable disease. Treatment was well tolerated with grade 1 or 2 gastrointestinal side effects the most frequent adverse events, mild visual disturbances were reported in $41 \%$ of cases, and grade 3-4 transaminases elevation in $6 \%$ of patients. All toxicities reversed on cessation of crizotinib (31). An expanded cohort of patients with $A L K$ translocated NSCLC was enrolled within the PROFILE 1001 trial. In a total of 149 patients, prevalently never smokers 
with adenocarcinoma histology and a median age of 52 years, crizotinib confirmed a noticeable efficacy, with an objective response rate of $60.8 \%$, including three complete and 84 partial responses. The median time to response was 7.9 weeks with a median duration of response of 49.1 weeks independent of age, sex, performance status (PS) or line of treatment. The stable disease was achieved in $21.7 \%$ of patients for a disease control rate of $82.5 \%$. Twenty-four patients $(16 \%)$ were anytherapy-naïve and reported a better median PFS which was 18.3 months versus 9.2 months achieved by the patients who received crizotinib as second-line or later treatment. Median PFS of the entire group was 10 months with an estimated 1-year OS of $75 \%$. Also in this larger number of patients treated with crizotinib, side effects were mainly grade 1 and 2 and recovered after stopping crizotinib treatment (32). Median OS was not reached; thus, a retrospective analysis was performed in order to estimate the possible median OS. Patients with $A L K$-positive NSCLC and treated with crizotinib (crizotinib group) were compared with both $A L K$-positive, crizotinib-naïve patients ( $A L K$-positive controls) and those without $A L K$ rearrangement ( $A L K$-negative controls, screened also for $E G F R$ mutational status and included only if EGFR was wild-type). The results were very interesting, as in fact, among the 82 patients of the crizotinib group, median OS was not reached; 1- and 2-year OS were 74 and $54 \%$, respectively, independent of age, sex, smoking history or ethnic origin. Thirty $A L K$-positive patients received crizotinib in the second- or third-line setting and reported a median OS significantly longer than that showed by the $23 A L K$-positive controls receiving any second-line therapy (median OS not reached versus 6 months), with 1 -year OS of $70 \%$ versus $44 \%$, and 2-year OS of 55 versus $12 \%$ [hazard ratio (HR) $0.36,95 \%$ confidence interval (CI) 0.17-0.75; $\mathrm{p}=0.004]$, respectively. A further comparison was performed between 36 crizotinib-naive, $A L K$-positive controls versus 253 wild-type controls, lacking $A L K$ or $E G F R$ alterations, with a median OS of 20 versus 15 months $(\mathrm{p}=0.244)$, respectively. Moreover, $56 A L K$-positive patients treated with crizotinib had similar OS to $63 E G F R$-positive patients treated with EGFR-TKIs with a median OS not reached versus 24 months, 1-year OS 71 versus $74 \%$, and 2-year OS 57 versus $52 \%$, respectively (33). Overall, these retrospective data are very interesting but should be interpreted with caution because deriving from indirect comparisons with potential biases.

PROFILE 1005 is a phase II trial of $A L K$-rearranged NSCLC designed as an open-label, single-arm study to evaluate the efficacy and safety of crizotinib in patients who had failed more than two lines of chemotherapy (34). PROFILE 1005 was a compendium trial for patients who were randomized to and progressed on the chemotherapy arm of the second-line randomized trial PROFILE 1007 which did not allow patients on the chemotherapy arm to crossover to crizotinib after disease progression (35). Instead, these patients could be enrolled into PROFILE 1005. A total of 901 patients received crizotinib and the first 261 patients were considered to be the mature population. Among all 901 patients, 15\% discontinued treatment due to adverse events and $10 \%$ had a dose reduction due to toxicity. The most frequent side effects, mostly grade $1-2$, were vision disorder (54\%), nausea (51\%), diarrhoea (44\%), vomiting (44\%) and constipation (37\%). In the mature population, the objective response rate was $60 \%$ with a disease control rate at 6 weeks of $86 \%$ and at 12 weeks of $75 \%$ with a median PFS of 8.1 months (34).

PROFILE 1007 compared crizotinib at the dose of $250 \mathrm{mg}$, orally, twice daily to chemotherapy, docetaxel or pemetrexed, in 347 advanced $A L K$-positive NSCLC previously treated with platinum-based chemotherapy. The primary endpoint was median PFS which was statistically better for the crizotinib arm with 7.7 months compared with the chemotherapy arm with 3.0 months (HR 0.49, 95\% CI 0.37-0.64; p<0.001). An impressive objective response rate in the second-line setting was observed with crizotinib (65 versus $20 \%$ in the chemotherapy arm; $p<0.0001)$. As expected, at the first interim analysis, no OS difference was reported between the two arms, with a median OS of 20.3 months for the crizotinib group versus 22.8 months for the chemotherapy group, respectively (HR 1.02, 95\% CI 0.68-1.54; $\mathrm{p}=0.54$ ). The significant crossover of the study influenced inevitably these results however, the data are still immature. Crizotinib common adverse events, mostly grade 1-2, were visual disorder, gastrointestinal side effects, and elevated liver aminotransferase levels, which were grade 3-4 in $16 \%$ of cases. Common adverse events with chemotherapy were fatigue, alopecia and dyspnea. Patients on crizotinib reported improved QoL, with time to deterioration in lung cancer symptoms significantly longer with crizotinib than with chemotherapy, with medians of 5.6 and 1.4 months (HR $0.54,95 \%$ CI $0.40-0.71 ; \mathrm{p}<0.0001$ ), respectively (35) (Table I).

Recently, crizotinib was shown to decrease testosterone in male patients (36). This issue was confirmed also in a larger sample of patients. In fact, the mean total testosterone levels, compared between 32 crizotinib-treated patients and 19 non-crizotinib-treated patients, was statistically lower in those receiving crizotinib $(\mathrm{p}=0.0012)$. Most of patients with low total levels had symptoms of androgen deficiency, such as fatigue, depression, sexual dysfunction, which improved with testosterone supplementation. The mechanism is not known, but it is interesting to note that $M E T$ and $A L K$ are both expressed in testes (37). When treating patients with new biologic agents, oncologists must face with the possibility of new toxicities, thus it is important to have a degree of adverse event monitoring above the 'standard'.

PROFILE 1014 is an ongoing phase III randomized trial comparing, as first-line therapy, crizotinib to platinum/ pemetrexed in $A L K$-positive non-squamous NSCLC patients. Crossover is allowed at progression and PFS is the primary endpoint (38).

After a rapid clinical development period and based on these results, crizotinib was approved almost worldwide for the use in previously treated $A L K$-rearranged advanced or metastatic NSCLC.

\section{Crizotinib resistance}

Inevitably, after an initial dramatic response to crizotinib, $A L K$-positive patients developed an acquired resistance to the treatment as with other TKIs. The onset of the resistance is on average within 1 or 2 years of TKI therapy. Mechanisms of acquired drug resistance might be classified into 2 main categories: the appearance of either a mutation or amplification 
Table I. Results from PROFILE studies in previously pretreated $A L K$-positive NSCLC patients.

\begin{tabular}{|c|c|c|c|c|c|c|}
\hline Study & $\begin{array}{l}\text { Phase } \\
\text { of study }\end{array}$ & Treatment & No.pts & $\begin{array}{l}\text { ORR } \\
(\%)\end{array}$ & $\begin{array}{c}\text { PFS } \\
\text { (months) }\end{array}$ & Toxicity \\
\hline $\begin{array}{l}\text { PROFILE } \\
1001(32)\end{array}$ & I & Crizotinib & $149^{\mathrm{a}}$ & 60.8 & 10 & $\begin{array}{l}\text { Grade } 3-4 \text { neutropenia }(n=9) \text {, raised alanine amino- } \\
\text { transferase }(n=6) \text {, hypophosphataemia }(n=6) \text {, } \\
\text { and lymphopenia }(n=6)\end{array}$ \\
\hline $\begin{array}{l}\text { PROFILE } \\
1005(34)\end{array}$ & II & Crizotinib & $261^{\mathrm{b}}$ & 60 & 8.1 & $\begin{array}{l}15 \% \text { discontinued treatment due to adverse events } \\
\text { and } 10 \% \text { had a dose reduction due to toxicity }\end{array}$ \\
\hline $\begin{array}{l}\text { PROFILE } \\
1007(35)\end{array}$ & III & $\begin{array}{l}\text { Crizotinib } \\
\text { vs docetaxel } \\
\text { or pemetrexed }\end{array}$ & $\begin{array}{l}173 \\
174\end{array}$ & $\begin{array}{l}65 \\
20\end{array}$ & $\begin{array}{l}7.7 \\
3.0\end{array}$ & $\begin{array}{l}\text { Grade } 3-4 \text { treatment related toxicities were } 33 \% \\
\text { versus } 32 \% \text {, serious adverse events were } 12 \% \\
\text { versus } 14 \% \text {, adverse events leading to } \\
\text { permanent discontinuation of the study drug } \\
\text { were } 6 \% \text { versus } 10 \% \text {, respectively }\end{array}$ \\
\hline
\end{tabular}

${ }^{\mathrm{a}} 16 \%$ were therapy-naive; ${ }^{\mathrm{b}}$ mature population; ${ }^{\mathrm{c} a m o n g} 901$ enrolled patients. NSCLC, non-small cell lung cancer; no. pts, number of patients; ORR, objective response rate; PFS, progression-free survival.

which alter the target gene; activation of alternative signalling pathways with tumour cells losing their dependency on the $A L K$-signalling pathway (Table II).

ALK mutation or amplification. The first evidence of mechanisms of resistance to crizotinib were described for a 28-year-old man, never smoker with advanced pretreated $E G F R$ wild-type and $A L K$-positive lung adenocarcinoma who relapsed after crizotinib therapy and was biopsied at progression. In this patient, two secondary point mutations (L1196M and $\mathrm{C} 1156 \mathrm{Y}$ ) within the kinase domain of the EML4-ALK were described, each mutation developing independently in subclones of the tumour and conferring marked resistance to two different ALK inhibitors (39). Furthermore, several reports showed that in approximately one-third of relapsing patients, the crizotinib resistance is mediated by the appearance of mutations located in the ALK TK domain. The most commonly identified resistance mutation is the 'gatekeeper mutation' L1196M which hinders crizotinib binding at its active site on ALK kinase (40-45). Some series reported that the amplification of the $A L K$ fusion gene with or without concurrent $A L K$ mutation leads to drug resistance $(43,44)$.

New pathway activation. One of the potential new pathway activation, which might mediate crizotinib resistance is that of EGFR signalling. In this setting, a double inhibition, of $A L K$ and $E G F R$, was effective $(40,43)$. Activation of $K R A S$ might represent another resistance mechanism in $A L K$-positive tumours due to the detection of new KRAS mutations in $A L K$-positive NSCLC resistant to crizotinib (43).

An analysis performed on $16 A L K$-positive NSCLC patients treated with crizotinib and re-biopsied at progression, suggested that crizotinib-resistant patients might be subdivided into two main groups. The $A L K$ dominant group, which represents approximately $50 \%$ of cases and includes $A L K$ kinase mutation (31\%) and $A L K$ fusion gene copy number gain (13\%), and the $A L K$ non-dominant group, which represents the
Table II. Main mechanisms of acquired crizotinib resistance (46).

NSCLC still addicted to $A L K$ signalling (50\%)

Secondary ALK mutations (main L1196M and

C1156Y) (31\%)

ALK copy number gain (13\%)

Both $(6 \%)$

Activation of alternative signalling pathways (50\%)

EGFR mutations (19\%)

KRAS mutations (12\%)

Unknown (including possible KIT, EGFR or

HER-2 variants (19\%)

other half, including emergence of alternate EGFR or KRAS mutations (31\%) and in $19 \%$ of cases in which the oncogene remained unknown and could rely on KIT, EGFR or HER-2 variants (46).

\section{Therapeutic strategies to overcome crizotinib resistance}

The knowledge of some mechanisms of resistance to crizotinib led to the development of new treatment strategies which are currently in clinical phase of investigation. Retrospective case series reported that in the presence of an oligo-progression crizotinib can be continued or resumed after local ablative therapy and still result in prolonged PFS (47). On the other hand, patients with significant and symptomatic progression during crizotinib treatment need an immediate change of therapy.

Second-generation ALK inhibitors. If the crizotinib resistance is mediated by $A L K$ mutation or amplification it means that the NSCLC is still addicted to $A L K$ signalling: this is the case 
Table III. Clinical results of main second-generation ALK inhibitors in advanced NSCLC.

\begin{tabular}{|c|c|c|c|}
\hline Characteristics & LDK378 (48) & Alectinib (50) & Alectinib (51) \\
\hline Phase of study & $\mathrm{I}$ & $\mathrm{I} / \mathrm{II}$ & I \\
\hline Escalating oral dose & $\leq 750 \mathrm{mg} /$ day & $\leq 300 \mathrm{mg}$ BID & $\leq 900 \mathrm{mg}$ BID \\
\hline No. of patients & 114 & 46 & 47 \\
\hline Crizotinib-naive & 35 & 46 & 0 \\
\hline Crizotinib-resistant & 79 & 0 & 47 \\
\hline ORR $(\%)$ & 58 & 93.5 & 54.5 \\
\hline PFS (months) & 8.6 & Not yet reached & Not yet reached \\
\hline \multirow[t]{2}{*}{ Grade 3-4 toxicity (\%) } & Diarrhoea (8) & Serious (11) & GGT, neutrophil, hypophosphatemia \\
\hline & Transaminase increase (10-19) & & in 2 pts each \\
\hline Recommended oral dose & $750 \mathrm{mg} /$ day & $300 \mathrm{mg}$ BID & $600 \mathrm{mg}$ BID \\
\hline
\end{tabular}

NSCLC, non-small cell lung cancer; ORR, objective response rate; PFS, progression-free survival; BID, bis in die; GGT; $\gamma$-glutamyl transferase.

in which a second generation ALK inhibitors might represent a promising treatment approach. These new $A L K$ inhibitors are structurally distinct from crizotinib and with the capability to inhibit also secondary acquired mutations $(40,43)$. Among the most promising next generation $A L K$ inhibitors, LDK378 is active in conventional $A L K$-positive tumours and in those expressing the mutation C1156Y. In a dose-escalating phase I single-arm study, the maximum tolerated dose, safety, pharmacokinetics and preliminary antitumour activity of LDK378 were investigated in $A L K$-positive solid tumours of any type. A total of 114 patients had $A L K$-positive NSCLC, 78 patients taking LDK378 at $750 \mathrm{mg} /$ day and 36 additional patients taking 400-750 mg/day. All 114 patients were evaluable for response, with 79 patients progressing during or following treatment with crizotinib, and 35 patients were crizotinib-naïve. The objective response rate was $60 \%$ in the 78 patients who received LDK378 at $750 \mathrm{mg} /$ day. In the 114 patients treated with LDK378 at doses $\geq 400 \mathrm{mg} /$ day, the objective response rate was $58 \%$, with a median duration of response of 8.2 months and a median PFS of 8.6 months. The most frequent adverse events were nausea $(73 \%)$, diarrhoea (72\%), vomiting (58\%) and fatigue (41\%). The most frequent grade 3-4 adverse events were increased alanine aminotransferase $(19 \%)$, increased aspartate aminotransferase $(10 \%)$ and diarrhoea (8\%) (48). These very impressive results led to the design of further trials which are actively recruiting worldwide. Among these a phase II multicenter, open label, single-arm study is evaluating the efficacy and safety of oral LDK378 $750 \mathrm{mg}$ once-daily in patients with ALK-positive advanced NSCLC who received 1-3 lines of therapy (including 1 platinum doublet) and progressed on crizotinib as the last therapy prior to study entry. The study was designed to enrol 137 patients (49).

Alectinib (CH5424802) was a potent, selective, ALK inhibitor with 10 -fold more potency than crizotinib and effectives against most of the mutations of the ALK domain. A multicentre, single-arm, open-label, phase I/II study, $A L K$-rearranged inhibitor-naïve advanced NSCLC patients received alectinib orally twice daily by dose escalation. In the phase I study, 24 patients were treated with $20-300 \mathrm{mg}$ twice daily. No dose limiting toxicities or grade 4 adverse events were reported, even with the highest dose. Thus, $300 \mathrm{mg}$ twice daily was the recommended dose for the phase II study. A total of 46 patients were treated with the recommended dose, with an objective response rate of $93.5 \%$ including two complete responses $(4.3 \%)$. Grade 3 treatment-related adverse events were reported in 12 (26\%) patients, serious side effects occurred in 5 patients (11\%). Median PFS has not been reached yet, since 40 of the 46 patients in the phase II portion remain on treatment (50). Another phase I study enrolled $47 A L K$-positive NSCLC patients who failed crizotinib and chemotherapy. No dose limiting toxicities were observed up to the highest dose tested (900 mg twice daily). Grade 3-4 adverse events included $\gamma$-glutamyl transferase increase $(n=2)$, neutrophil decrease $(n=2)$, hypophosphatemia $(n=2)$, hyperglycemia, syncope, renal failure and pericardial effusion ( $n=1$ each), but no grade 3 nausea, vomit, diarrhoea, oedema were reported. The objective response rate was $54.5 \%$ across all dose cohorts for all patients, all partial responses, with a median duration on treatment $>4$ months. Alectinib at the oral dose of $600 \mathrm{mg}$ twice daily was chosen as recommended phase II dose based on pharmacokinetics, efficacy and tolerability (51). In both trials, the promising antitumour activity of alectinib was observed in $A L K$-positive patients including also those who failed crizotinib. Therefore, a global single-arm phase II study of alectinib in crizotinib-resistant $A L K$-positive NSCLC patients is ongoing (52) (Table III).

AP26113 is a novel dual ALK-/EGFR-TKI that potently inhibits mutated forms including the ALK L1196M and EGFR T790M mutations. A phase I/II open-label, multicenter study enrolled 44 patients with advanced solid tumours, including 37 patients with NSCLC, refractory to available therapies or for whom no standard treatment exists. AP26113 was administered with escalating once-daily oral doses. Most common 3-4 treatment-related adverse event was diarrhoea, reported in $5 \%$ of cases. Two dose limiting toxicities were observed at $240 \mathrm{mg}$ (grade 3 alanine aminotransferase increase) and at $300 \mathrm{mg}$ (grade 4 dyspnea). Thus, doses $<300 \mathrm{mg}$ are 
being explored further in the ongoing phase II expansion, which includes 4 cohorts: $A L K$-positive NSCLC naïve or resistant to prior ALK-targeted therapy, EGFR mutated NSCLC resistant to EGFR-targeted therapy, other cancers with abnormalities in $A L K$ or other AP26113 targets (53).

Heat-shock protein 90 inhibitors. ALK fusion proteins, including those with resistance mutations, are known heat shock protein 90 (HSP90) clients. HSP90 inhibitors bind in the ATP-binding pocket of the enzyme, and prevent it from regulating the activation and stability of its client proteins, including $A L K$. Thus, inhibition of HSP90 resulted in reduction of the expression of EML4-ALK through proteasome-mediated degradation (41,54). Unfortunately, to date no clinical trial has been conducted to investigate HSP90 inhibitors specifically addressed to patients with $A L K$-positive NSCLC, but retrospective analysis showed promising results of HSP90 inhibitors in this setting (55-57). Ganetespib (STA-9090) an HSP90 inhibitor, was administered as monotherapy at the dose of $200 \mathrm{mg} / \mathrm{m}^{2}$ weekly, for 3 weeks with a one-week rest, to 99 patients heavily pretreated for advanced NSCLC. Patients were subdivided in 3 cohorts: $E G F R$-mutated, $K R A S$-mutated, no $E G F R$ - or $K R A S$-mutated. In this last cohort, 4 partial responses were reported, and all in $A L K$-positive crizotinibnaïve patients. However, $A L K$ gene rearrangements were retrospectively detected by FISH in 1 case or PCR-based assays in the other 3 cases. The most common adverse events reported in all patients were diarrhoea, fatigue, nausea and anorexia (55). Based on these earlier results, to evaluate whether or not this approach will be effective the CHIARA trial (CHaperone Inhibition in ALK Rearranged lung cAncer) is ongoing. In this phase II trial, ganetespib monotherapy is administered to previously treated patients with stage IIIB/ IV NSCLC harbouring an $A L K$ gene rearrangement and who have not been previously treated with a direct ALK inhibitor. Primary endpoint is objective response rate with approximately 100 patients planned to be enrolled (58). To mitigate the development of acquired resistance, a dual inhibition of critical signalling pathways is being investigated. A phase I/II study is evaluating the combination of crizotinib and ganetespib in previously treated patients with NSCLC $A L K$-positive not pretreated with any specific inhibitor, with the primary endpoint to define the maximum tolerated dose to be investigated in the subsequent phase II trial (59). This trial should give more information on whether this approach is more effective than either therapy alone, and whether dual treatment prevents development of acquired resistance.

Another HSP90 inhibitor is retaspimycin hydrochloride (IPI-504), which was investigated in a phase II trial at the starting dose of $400 \mathrm{mg} / \mathrm{m}^{2}$ on days $1,4,8$ and 11 of a 21-day cycle and then at the dose of $225 \mathrm{mg} / \mathrm{m}^{2}$ due to hepatotoxicities observed at the highest dose in another trial. A total of 76 patients with advanced NSCLC and heavily pretreated including a line with EGFR-TKI were enrolled. Among these patients, 3 were $A L K$-positive, two had partial responses and the third had prolonged stable disease ( 7.2 months, $24 \%$ reduction in tumour size). The most common grades 1 and 2 adverse events included fatigue, nausea and diarrhoea. Grade $\geq 3$ hepatotoxicities were observed in nine patients (11.8\%) (56).
AUY922, is a highly potent, non-geldanamycin, HSP90 inhibitor which was tested in a phase II study including also $A L K$-positive NSCLC patients. AUY922 was administered at the weekly dose of $70 \mathrm{mg} / \mathrm{m}^{2}$ to 121 previously treated NSCLC patients. In the total of $22 A L K$-positive patients, 7 objective responses (32\%) were reported, 3 of which among the 14 crizotinib-resistant NSCLC patients; the disease control rate was $59 \%$ (100\% in the crizotinib-naive group and $36 \%$ in the crizotinib-resistant group). The most frequent adverse events, mainly grade $1-2$, were eye disorders $(77 \%)$, diarrhoea $(74 \%)$ and nausea (46\%) (57). AUY922 is currently being investigated in $A L K$-positive patients in two trials. A phase II study is evaluating AUY922 in $A L K$-positive patients resistant to an ALK-TKI therapy with the objective response rate as primary endpoint and the estimated enrolment of 20 patients (60). LDK378 and AUY922 were administered within a phase Ib study to patients with $A L K$-positive NSCLC already pretreated with crizotinib. The primary endpoint is the incidence rate of dose limiting toxicities with the estimated enrolment of 142 patients (61).

\section{Special topics}

Further interesting considerations arose during crizotinib biological and clinical investigations.

Thymidylate synthase and pemetrexed. In a retrospective analysis, the efficacy of pemetrexed in terms of PFS was evaluated in 89 advanced NSCLC studying the relationship with specific molecular subtype. Patients with $A L K$ gene rearrangements had a longer median PFS on pemetrexed than on KRAS mutant, $E G F R$ mutant, or triple-negative patients ( 9 months compared with 7,5.5 and 4 months, respectively). The data were confirmed also by the multivariate analysis in which the only statistically significant variable associated with prolonged PFS on pemetrexed was $A L K$-positivity (HR 0.36; $\mathrm{p}=0.0051$ ) (62). Another retrospective analysis confirmed the previous data. Fifteen $A L K$-positive patients reported a better objective response rate than 43 EGFR-mutated patients and 37 wild-type patients with 46.7, 4.7 and $16.2 \%(\mathrm{p}=0.001)$, respectively. Time to progression (TTP) was also in favour of $A L K$-positive patients $(9.2,1.4$ and 2.9 months, respectively; $\mathrm{p}=0.001$ ) (63).

This correlation might be explained with the lower concentration of thymidylate synthase (TS), the main target of pemetrexed, in $A L K$-positive tumours $(63,64)$.

The largest retrospective analysis compared 121 $A L K$-positive NSCLC patients with 266 patients with $A L K$-negative, $E G F R$-wild-type NSCLC, including 79 with $K R A S$ mutations. Among $70 A L K$-positive patients treated with a platinum/pemetrexed regimen, the median PFS was 7.3 months while it was 5.5 months for $51 A L K$-positive patients treated with single-agent pemetrexed or non-platinum/ pemetrexed combinations. PFS of $A L K$-negative patients, on all pemetrexed-based regimens, was similar to that of $A L K$-positive patients, except in first-line platinum/pemetrexed where the median PFS was 4.2 and 5.4 months, in patients with $K R A S$-mutation and wild-type, respectively (65).

Contrary to previous data, this large retrospective analysis did not report any statistical advantage for $A L K$-positive patients treated with pemetrexed-based therapy. 
Table IV. Main clinical results of pemetrexed therapy in ALK-translocated NSCLC patients.

\begin{tabular}{|c|c|c|c|c|c|}
\hline Characteristics & $\begin{array}{c}\text { Camidge et al (62) } \\
2011\end{array}$ & $\begin{array}{l}\text { Lee } \text { et al (63) } \\
\quad 2011\end{array}$ & $\begin{array}{c}\text { Shaw et al }(65)^{\mathrm{a}} \\
2013\end{array}$ & $\begin{array}{c}\text { Shaw et al }(65)^{\mathrm{b}} \\
2013\end{array}$ & $\begin{array}{c}\text { Shaw et al (35) } \\
2013\end{array}$ \\
\hline Type of study & Retrospective & Retrospective & Retrospective & Retrospective & Prospective \\
\hline $\begin{array}{l}\text { Line of pemetrexed } \\
\text { therapy }\end{array}$ & Any line & $\geq 2$ nd-line & Any line & Any line & 2nd-line \\
\hline \multicolumn{6}{|l|}{ No. of patients } \\
\hline$A L K$-rearrangements & 19 & 15 & 70 & 51 & 99 \\
\hline$E G F R$-mutations & 12 & 43 & - & - & - \\
\hline$K R A S$-mutations & 21 & - & 112 & 75 & - \\
\hline Wild-type & 37 & 37 & 49 & 30 & - \\
\hline \multicolumn{6}{|l|}{ ORR (\%) } \\
\hline$A L K$-rearrangements & 42 & 46.7 & Not reported & Not reported & 29 \\
\hline$E G F R$-mutations & 30 & 4.7 & & & - \\
\hline$K R A S$-mutations & 37 & - & & & - \\
\hline Wild-type & 14 & 16.2 & & & - \\
\hline \multicolumn{6}{|l|}{ PFS (months) } \\
\hline$A L K$-rearrangements & 9.0 & 9.2 & $7.3^{\mathrm{c}}$ & 5.5 & 4.2 \\
\hline$E G F R$-mutations & 5.5 & 1.4 & - & - & - \\
\hline$K R A S$-mutations & 7.0 & - & $5.9^{c}$ & 3.9 & - \\
\hline Wild-type & 4.0 & 2.9 & $4.5^{\mathrm{c}}$ & 7.8 & - \\
\hline
\end{tabular}

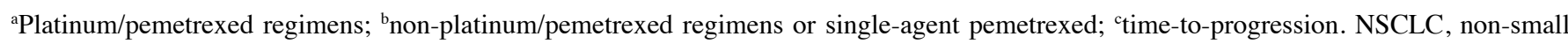
cell lung cancer; ORR, objective response rate; PFS, progression-free survival.

These contrasting results could be directly addressed by the prospective studies such as PROFILE 1007 and PROFILE 1014. To date, only the results of PROFILE 1007 are available, showing an interesting relationship between $A L K$-positivity and sensitivity to pemetrexed treatment. Patients treated with pemetrexed experienced better objective response rates as compared to those treated with docetaxel (29.3 and 6.9\%, respectively) and better PFS (4.2 and 2.6 months, respectively). It is important to emphasise that the study was not designed to compare the two chemotherapeutics. Moreover, the choice between pemetrexed or docetaxel was left to the investigator and not to randomization (35) (Table IV).

The final results of the PROFILE 1014 trial are awaited also to better understand the activity of pemetrexed in $A L K$-positive NSCLC patients.

Crizotinib for ROS1-rearrangements. ROS1 is a receptor tyrosine kinase of the insulin receptor family, shown to fuse at exons $32,34,35$ or 36 with multiple partners in NSCLC (TPM3, SDC4, SLC34A2, CD74, EZR, LRIG3 and FIG). These chimeric proteins, found in approximately $1-2 \%$ of NSCLC patients, maintain constitutive ROS1 kinase activity, leading to persistent downstream signalling and transforming ability via enhanced cell growth, proliferation and decreased apoptosis $(66,67)$. Like $A L K$-positive NSCLC patients, ROS1-positive NSCLC patients tend to be younger (median age, 49.5 years), never-smokers, have a histological diagnosis of adenocarcinoma, and seem to be mutually exclusive with other gene alterations (68).

Preclinical studies of cell lines harbouring ROS1 rearrangements and clinical evidence on a single $C D 74$ ROS1-positive NSCLC patient showed sensitivity to crizotinib $(68,69)$. Thirteen $R O S 1$-positive NSCLC patients, all previously treated, received crizotinib at the standard dose of $250 \mathrm{mg}$ twice daily. Patients were young with a median age of 47 years, all with adenocarcinoma histology, and all but one were never-smokers. The objective response rate was $54 \%$, with a disease control rate at 8 weeks of $85 \%$ (70). A progression of disease is reported also for ROS1-positive patients after a response to crizotinib treatment. A crizotinib resistance due to an acquired mutation leading to a glycine-to-arginine substitution at codon 2032 in the ROS1 kinase domain was demonstrated in a $R O S 1$-positive patient initially responding to crizotinib. This mutation confers resistance to crizotinib through steric interference with drug binding (71).

Brain metastases. The incidence of brain metastases in $A L K$-positive NSCLC patients was described to be $\leq 46 \%$ (72). A case report showed development of brain metastases under crizotinib therapy, despite an objective response of extracranial lesions, in an $A L K$-positive NSCLC patient. Measurement of the levels of crizotinib in the plasma and cerebrospinal fluid (CSF) indicated a poor penetration of the drug into the brain, thus potentially hindering efficacy in metastatic brain tumours 
(73). Further reports underlined this aspect reporting several cases in which $A L K$-positive NSCLC patients reported a brain progression of disease despite a shrinkage of extracranial tumour sites (74-76). On the contrary, other reports showed slight reduction of brain metastases (77) or response (78) with crizotinib therapy even if with a different schedule.

Interesting results on brain metastases were gained from phase I/II trials with alectinib $(50,79)$. Among the 46 patients enrolled in the phase II portion of the first study (50), 15 (33\%) patients with known identified brain metastases, of whom $12(26 \%)$ were previously irradiated and three $(7 \%)$ were clinically stable without symptoms at baseline. No progression of brain metastases in any of the patients was reported, although previous radiotherapy might have affected the natural history of brain disease. Two of the three patients who had baseline brain metastases and had not received previous radiotherapy continued alectinib for $>300$ days without brain progression (50). In the second trial (79), 21 out of 47 enrolled patients had brain metastases at baseline, and 4 received no prior brain irradiation. In these 4 patients, two complete and one partial responses with one stable disease were reported. Among the 17 patients with brain metastases and previously irradiated, one patient progressed in both systemic and brain sites, three progressed only in systemic sites and the other 13 patients are still on treatment with one complete response (79).

In both trials, alectinib demonstrated consistent and rapid clinical activity in brain metastases in $A L K$-positive NSCLC patients who progressed on crizotinib. This is likely due in part to low penetration of crizotinib into the central nervous system. In fact, the blood-brain barrier (BBB) contributes to brain homeostasis by protecting the brain from potentially harmful endogenous and exogenous substances. The efflux transporter P-glycoprotein (Pgp) is a key element of the BBB that can actively transport a huge variety of lipophilic drugs out of the brain capillary endothelial cells that form the BBB (80). Crizotinib is a good Pgp substrate, but not alectinib. Moreover, preclinical studies in the central nervous system implantation models suggest a promising antitumour activity of alectinib against brain lesions (79).

Of course, further studies specifically addressing this issue must better clarify the potential role of alectinib also in this setting.

\section{Conclusion}

Histology and molecular analyses are the cornerstone in the initial diagnosis of NSCLC, and are key determinants to address the appropriate strategy of treatment. Among the first targeted agents approved for molecular selected NSCLC patients were EGFR-TKIs, gefitinib, erlotinib and afatinib in $E G F R$-mutated patients. $A L K$ translocations were discovered as new molecular drivers for which specific inhibitors are in development. The first clinical trials provided evidence for the use of ALK-TKI crizotinib, changing the therapeutic options for this subgroup of approximately $5 \%$ of $A L K$-positive NSCLC patients. The emergence of crizotinib took place over a short period of just four years, from identification of the target to approval of the drug, leading to the availability of another potential therapeutic option and the challenge of identifying suitable patients effectively and efficiently through the integration of $A L K$ identification into routine clinical practice. The dramatic clinical responses achieved in patients with $A L K$-positive NSCLC with the use of crizotinib are of limited durability, because patients will ultimately develop acquired resistance to crizotinib. Concerning this issue, in the presence of known oncogenic drivers in tumours, an important consideration is that serial biopsies should be mandatory, when possible, to detect resistance mechanisms and to define further appropriate treatment strategies for progressing patients. Therefore, additional therapeutic approaches to prevent acquired resistance to crizotinib or effectively treat crizotinib-resistant disease are greatly needed. Several drugs in early phase trials demonstrated promising results in crizotinib-resistant NSCLC patients, but further randomized trials, to date ongoing, are needed to clarify their role in this setting.

\section{References}

1. Rossi A, Torri V, Garassino MC, Porcu L and Galetta D: The impact of personalized medicine on survival: comparisons of results in metastatic breast, colorectal and non-small-cell lung cancers. Cancer Treat Rev 40: 485-494 2014.

2. Scagliotti GV, Parikh P, von Pawel J, et al: Phase III study comparing cisplatin plus gemcitabine with cisplatin plus pemetrexed in chemotherapy-naive patients with advanced-stage non-small-cell lung cancer. J Clin Oncol 26: 3543-3551, 2008.

3. Sandler A, Gray R, Perry MC, et al: Paclitaxel-carboplatin alone or with bevacizumab for non-small-cell lung cancer. N Engl J Med 355: 2542-2550, 2006.

4. Rossi A, Pasquale R, Esposito C and Normanno N: Should epidermal growth factor receptor tyrosine kinae inhibitors be considered ideal drugs for the treatment of selected advanced non-small cell lung cancer patients? Cancer Treat Rev 39: 489-497, 2013.

5. Soda M, Choi YL, Enomoto M, et al: Identification of the transforming EML4-ALK fusion gene in non-small-cell lung cancer. Nature 448: 561-566, 2007.

6. Amin HM and Lai R: Pathobiology of $\mathrm{ALK}^{+}$anaplastic large-cell lymphoma. Blood 110: 2259-2267, 2007.

7. Chiarle R, Voena C, Ambrogio C, Piva R and Inghirami G: The anaplastic lymphoma kinase in the pathogenesis of cancer. Nat Rev Cancer 8: 11-23, 2008.

8. Sasaki T, Rodig SJ, Cirieac LR and Janne PA: The biology and treatment of EML4-ALK non-small cell lung cancer. Eur J Cancer 46: 1773-1780, 2010.

9. Takeuchi K, Choi YL, Togashi Y, et al: KIF5B-ALK, a novel fusion oncokinase identified by an immunohistochemistry-based diagnostic system for ALK-positive lung cancer. Clin Cancer Res 15: 3143-3149, 2009.

10. Rikova K, Guo A, Zeng Q, et al: Global survey of phosphotyrosine signaling identifies oncogenic kinases in lung cancer. Cell 131: 1190-1203, 2007.

11. Inamura K, Takeuchi K, Togashi Y, et al: EML4-ALK fusion is linked to histological characteristics in a subset of lung cancers. J Thorac Oncol 3: 13-17, 2008.

12. Rodig SJ, Mino-Kenudson M, Dacic S, et al: Unique clinicopathologic features characterize ALK-rearranged lung adenocarcinoma in the western population. Clin Cancer Res 15: 5216-5223, 2009.

13. Shaw AT, Yeap BY, Mino-Kenudson M, et al: Clinical features and outcome of patients with non-small-cell lung cancer who harbor EML4-ALK. J Clin Oncol 27: 4247-4253, 2009.

14. Wong DW, Leung EL, So KK, et al: The EML4-ALK fusion gene is involved in various histologic types of lung cancers from nonsmokers with wild-type EGFR and KRAS. Cancer 115: 1723-1733, 2009.

15. Zhang X, Zhang S, Yang X, et al: Fusion of EML4 and ALK is associated with development of lung adenocarcinomas lacking EGFR and KRAS mutations and is correlated with ALK expression. Mol Cancer 9: 188, 2010.

16. Koh Y, Kim DW, Kim TM, et al: Clinicopathologic characteristics and outcomes of patients with anaplastic lymphoma kinase-positive advanced pulmonary adenocarcinoma. J Thorac Oncol 6: 905-912, 2011. 
17. Barlesi F, Blons H, Beau-Faller M, et al: Biomarkers (BM) France: results of routine EGFR, HER2, KRAS, BRAF, PI3KCA mutations detection and EML4-ALK gene fusion assessment on the first 10,000 non-small cell lung cancer (NSCLC) patients (pts). J Clin Oncol 31: 8000, 2013.

18. Johnson BE, Kris MG, Berry LD, et al: A multicenter effort to identify driver mutations and employ targeted therapy in patients with lung adenocarcinomas: The Lung Cancer Mutation Consortium (LCMC). J Clin Oncol 31: 8019, 2013.

19. Rosell R, Massuti Sureda B, Costa C, et al: Concomitant actionable mutations and overall survival (OS) in EGFR-mutant non-small-cell lung cancer (NSCLC) patients (p) included in the EURTAC trial: EGFR L858R, EGFR T790M, TP53 R273H and EML4-ALK. Ann Oncol 23 (Suppl 9): ixe22 (LBA31), 2012.

20. Rosell R, Carcereny E, Gervais R, et al: Erlotinib versus standard chemotherapy as first-line treatment for European patients with advanced EGFR mutation-positive non-small-cell lung cancer (EURTAC): a multicenter, open-label, randomised phase 3 trial. Lancet Oncol 13: 239-246, 2012

21. Lindeman NI, Cagle PT, Beasley MB, et al: Molecular testing guidelinefor selection of lung cancer patients for EGFR and ALK tyrosine kinase inhibitors; guideline from the College of American Pathologists, International Association for the Study of Lung Cancer, and Association for Molecular Pathology. J Thorac Oncol 8: 823-859, 2013.

22. Camidge DR, Kono SA, Flacco A, et al: Optimizing the detection of lung cancer patients harboring anaplastic lymphoma kinase (ALK) gene rearrangements potentially suitable for ALK inhibitor treatment. Clin Cancer Res 16: 5581-5590, 2010.

23. Park HS, Lee JK, Kim DW, et al: Immunohistochemical screening for anaplastic lymphoma kinase (ALK) rearrangement in advanced non-small cell lung cancer patients. Lung Cancer 77: 288-292, 2012

24. Minca EC, Portier BP, Wang Z, et al: ALK status testing in non-small cell lung carcinoma: correlation between ultrasensitive IHC and FISH. J Mol Diagn 15: 341-346, 2013.

25. Sholl LM, Weremowicz S, Gray SW, et al: Combined use of ALK immunohistochemistry and FISH for optimal detection of ALK-rearranged lung adenocarcinomas. J Thorac Oncol 8: 322-328, 2013.

26. Martinez P, Hernández-Losa J, Montero MÁ, et al: Fluorescence in situ hybridization and immunohistochemistry as diagnostic methods for ALK positive non-small cell lung cancer patients. PLoS One 8: e52261, 2013.

27. Conklin CM, Craddock KJ, Have C, et al: Immunohistochemistry is a reliable screening tool for identification of ALK rearrangement in non-small-cell lung carcinoma and is antibody dependent. J Thorac Oncol 8: 45-51, 2013.

28. Christensen JG, Zou HY, Arango ME, et al: Cytoreductive antitumor activity of PF-2341066, a novel inhibitor of anaplastic lymphoma kinase and c-Met, in experimental models of anaplastic large-cell lymphoma. Mol Cancer Ther 6: 3314-3322, 2007.

29. Cui JJ, Tran-Dubé M, Shen H, et al: Structure based drug design of crizotinib (PF-02341066), a potent and selective dual inhibitor of mesenchymal-epithelial transition factor (c-MET) kinase and anaplastic lymphoma kinase (ALK). J Med Chem 54: 6342-6363, 2011.

30. Kwak EL, Camidge DR, Clark J, et al: Clinical activity observed in a phase I dose escalation trial of an oral c-met and ALK inhibitor, PF-02341066. J Clin Oncol 27 (15S): 148s, 3509, 2009.

31. Kwak EL, Bang YJ, Camidge DR, et al: Anaplastic lymphoma kinase inhibition in non-small-cell lung cancer. $\mathbf{N}$ Engl J Med 363: 1693-1703, 2010.

32. Camidge DR, Bang Y-B, Kwak EL, et al: Activity and safety of crizotinib in patients with ALK-positive non-small-cell lung cancer: updated results from a phase 1 study. Lancet Oncol 13: 1011-1019, 2012

33. Shaw AT, Yeap BY, Solomon BJ, et al: Effect of crizotinib on overall survival in patients with advanced non-small-cell lung cancer harbouring ALK gene rearrangement: a retrospective analysis. Lancet Oncol 12: 1004-1012, 2011.

34. Kim D, Ahn M, Yang P, et al: Updated results of a global phase II study with crizotinib in advanced ALK-positive non-small cell lung cancer (NSCLC). Ann Oncol 23 (Suppl 9): ix402, 1230PD, 2012.

35. Shaw AT, Kim DW, Nakagawa K, et al: Crizotinib versus chemotherapy in advanced ALK-positive lung cancer. N Engl J Med 368: 2385-2394, 2013
36. Weickhardt AJ, Rothman MS, Salian-Mehta S, et al: Rapid-onset hypogonadism secondary to crizotinib use in men with metastatic nonsmall cell lung cancer. Cancer 118: 5302-5309, 2012.

37. Weickhardt AJ, Doebele RC, Purcell WT, et al: Symptomatic reduction in free testosterone levels secondary to crizotinib use in male cancer patients. Cancer 119: 2383-2390, 2013.

38. A clinical trial testing the efficacy of crizotinib versus standard chemotherapy pemetrexed plus cisplatin or carboplatin in patients with ALK positive non squamous cancer of the lung (PROFILE 1014). http://clinicaltrials.gov/ct2/show/NCT01154140. Accessed March 15, 2014.

39. Choi YL, Soda M, Yamashita Y, et al: EML4-ALK mutations in lung cancer that confer resistance to ALK inhibitors. N Engl J Med 363: 1734-1739, 2010.

40. Sasaki T, Koivunen J, Ogino A, et al: A novel ALK secondary mutation and EGFR signaling cause resistance to ALK kinase inhibitors. Cancer Res 71: 6051-6060, 2011.

41. Katayama R, Khan TM, Benes C, et al: Therapeutic strategies to overcome crizotinib resistance in non-small cell lung cancers harboring the fusion oncogene EML4-ALK. Proc Natl Acad Sci USA 108: 7535-7540, 2011.

42. Zhang S, Wang F, Keats J, et al: Crizotinib-resistant mutants of EML4-ALK identified through an accelerated mutagenesis screen. Chem Biol Drug Des 78: 999-1005, 2011.

43. Katayama R, Shaw AT, Khan TM, et al: Mechanisms of acquired crizotinib resistance in ALK-rearranged lung cancers. Sci Transl Med 4: 120ra17, 2012.

44. Doebele RC, Pilling AB, Aisner DL, et al: Mechanisms of resistance to crizotinib in patients with ALK gene rearranged non-small cell lung cancer. Clin Cancer Res 18: 1472-1482, 2012.

45. Lovly CM and Pao W: Escaping ALK inhibition: mechanisms of and strategies to overcome resistance. Sci Transl Med 4: 120ps2, 2012.

46. Doebele RC, Aisner DL, Le AT, et al: Analysis of resistance mechanisms to ALK kinase inhibitors in $\mathrm{ALK}^{+}$NSCLC patients. J Clin Oncol 30 (15S): 7504, 2012.

47. Camidge DR, Bang Y, Kwak EL, et al: Progression-free survival (PFS) from a phase I study of crizotinib (PF-02341066) in patients with ALK-positive non-small cell lung cancer (NSCLC). J Clin Oncol 29 (15S): 2501, 2011.

48. Shaw AT, Mehra R, Kim DW, et al: Clinical activity of the ALK inhibitor LDK378 in advanced, ALK-positive NSCLC. J Clin Oncol 31 (15S): 8010, 2013.

49. Shaw AT, Mok T, Spigel DR, et al: A phase II single-arm study of LDK378 in patients with ALK-activated $\left(\mathrm{ALK}^{+}\right)$non-small cell lung cancer (NSCLC) previously treated with chemotherapy and crizotinib (CRZ). J Clin Oncol 31 (15S): TPS8119, 2013.

50. Seto T, Kiura K, Nishio M, et al: CH5424802 (RO5424802) for patients with $A L K$-rearranged advanced non-small-cell lung cancer (AF-001JP study): a single-arm, open-label, phase 1-2 study. Lancet Oncol 14: 590-598, 2013.

51. Gadgeel S, Ou SH, Chiappori AA, et al: A Phase 1 dose escalation study of a new ALK inhibitor, CH5424802/RO5424802, in ALK+ non-small cell lung cancer (NSCLC) patients who have failed crizotinib (AF-002JG/NP28761, NCT01588028). J Thorac Oncol 8 (Suppl 2): S199, O16.06, 2013.

52. A study of RO5424802 in patients with non-small cell lung cancer who have ALK mutation and failed crizotinib treatment. http://clinicaltrials.gov/show/NCT01801111. Accessed March 15, 2014.

53. Camidge DR, Bazhenova L, Salgia R, et al: First-in-human dosefinding study of the ALK/EGFR inhibitor AP26113 in patients with advanced malignancies: updated results. J Clin Oncol 31 (15S): 8031, 2013.

54. Chen Z, Sasaki T, Tan X, et al: Inhibition of ALK, PI3K/MEK, and HSP90 in murine lung adenocarcinoma induced by EML4-ALK fusion oncogene. Cancer Res 70: 9827-9836, 2010.

55. Socinski MA, Goldman J, El-Hariry I, et al: A multicenter phase II study of ganetespib monotherapy in patients with genotypically defined advanced non-small cell lung cancer. Clin Cancer Res 19: 3068-3077, 2013.

56. Sequist LV, Gettinger S, Senzer NN, et al: Activity of IPI-504, a novel heat-shock protein 90 inhibitor, in patients with molecularly defined non-small-cell lung cancer. J Clin Oncol 28: 4953-4960, 2010.

57. Felip E, Carcereny E, Barlesi F, et al: Phase II activity of the Hsp90 inhibitor AUY922 in patients with ALK-rearranged $\left(\mathrm{ALK}^{+}\right)$or EGFR-mutated advanced non-small cell lung cancer (NSCLC). Ann Oncol 23 (Suppl 9): ix152-ix174, 438, 2012. 
58. A study of ganetespib in subjects with ALK-positive non-smallcell lung cancer (NSCLC) (CHIARA). http://clinicaltrials.gov/ show/NCT01562015. Accessed March 15, 2014.

59. Crizotinib and ganetespib (STA-9090) in ALK positive lung cancers. http://clinicaltrials.gov/show/NCT01579994. Accessed March 15, 2014.

60. AUY922 for advanced ALK-positive NSCLC. http://clinicaltrials.gov/show/NCT01752400. Accessed March 15, 2014.

61. Phase Ib study of LDK378 and AUY922 in ALK-rearranged non-small cell lung cancer. http://clinicaltrials.gov/show/ NCT01772797. Accessed March 15, 2014.

62. Camidge DR, Kono SA, Lu X, et al: Anaplastic lymphoma kinase gene rearrangements in non-small cell lung cancer are associated with prolonged progression-free survival on pemetrexed. J Thorac Oncol 6: 774-780, 2011.

63. Lee JO, Kim TM, Lee SH, et al: Anaplastic lymphoma kinase translocation: a predictive biomarker of pemetrexed in patients with non-small cell lung cancer. J Thorac Oncol 6: 1474-1480, 2011.

64. Takezawa K, Okamoto I, Okamoto W, et al: Thymidylate synthase as a determinant of pemetrexed sensitivity in non-small cell lung cancer. Br J Cancer 104: 1594-1601, 2011.

65. Shaw AT, Varghese AM, Solomon BJ, et al: Pemetrexed-based chemotherapy in patients with advanced, ALK-positive non-small cell lung cancer. Ann Oncol 24: 59-66, 2013.

66. Rimkunas VM, Crosby KE, Li D, et al: Analysis of receptor tyrosine kinase ROS1-positive tumors in non-small cell lung cancer: identification of a FIG-ROS1 fusion. Clin Cancer Res 18 : 4449-4457, 2012.

67. Takeuchi K, Soda M, Togashi Y, et al: RET, ROS1 and ALK fusions in lung cancer. Nat Med 18: 378-381, 2012.

68. Bergethon K, Shaw AT, Ou SH, et al: ROS1 rearrangements define a unique molecular class of lung cancers. J Clin Oncol 30 863-870, 2012.

69. Yasuda H, de Fiqueiredo-Pontes LL, Kobayashi S and Costa DB Preclinical rationale for use of the clinically available multitargeted tyrosine kinase inhibitor crizotinib in ROS1-translocated lung cancer. J Thorac Oncol 7: 1086-1090, 2012.

70. Shaw AT, Camidge DR, Engelman JA, et al: Clinical activity of crizotinib in advanced non-small cell lung cancer (NSCLC) harboring ROS1 gene rearrangement. J Clin Oncol 30 (15S): 7508, 2012.
71. Awad MM, Katayama R, McTigue M, et al: Acquired resistance to crizotinib from a mutation in CD74-ROS1. N Engl J Med 368; 2395-2401, 2013.

72. Weickhardt AJ, Scheier B, Burke JM, et al: Local ablative therapy of oligoprogressive disease prolongs disease control by tyrosine kinase inhibitors in oncogene addicted non-small cell lung cancer. J Thorac Oncol 7: 1807-1814, 2012.

73. Costa DB, Kobayashi S, Pandya SS and Yeo WL: CSF concentration of the anaplastic lymphoma kinase inhibitor crizotinib. J Clin Oncol 29: e443-e445, 2012.

74. Chun SG, Choe KS, Iyengar P, Yordy JS and Timmerman RD: Isolated central nervous system progression on crizotinib: an Achilles heel of non-small cell lung cancer with EML4-ALK translocations? Cancer Biol Ther 13: 1376-1383, 2012.

75. Maillet D, Martel-Lafay I, Arpin D and Perol M: Ineffectiveness of crizotinib on brain metastases in two cases of lung adenocarcinoma with EML4-ALK rearrangement. J Thorac Oncol 8: e30-e31, 2013.

76. Kim YH, Ozasa H, Nagai H, et al: High-dose crizotinib for brain metastases refractory to standard-dose crizotinib. J Thorac Oncol 8: e85-e86, 2013.

77. Kinoshita Y, Koga Y, Sakamoto A and Hidaka K: Long-lasting response to crizotinib in brain metastases due to EML4-ALKrearranged non-small-cell lung cancer. BMJ Case Rep 2013 doi: $10.1136 /$ bcr-2013-200867.

78. Peled N, Zach L, Liran O, Ilouze M, Bunn PA Jr and Hirsch FR: Effective crizotinib schedule for brain metastases in ALK rearrangement metastatic non-small-cell lung cancer. J Thorac Oncol 8: e112-e113, 2013

79. Ou SH, Gadgeel S, Chiappori AA, et al: Consistent therapeutic efficacy of CH5424802/RO5424802 in brain metastases among crizotinib-refractory ALK-positive non-small cell lung cancer (NSCLC) patients in an ongoing phase I/II study (AF-002JG/ NP28761, NCT01588028). J Thorac Oncol 8 (Suppl 2): S200 O16.07, 2013.

80. Loscher W and Potschka H: Blood-brain barrier active efflux transporters: ATP-binding cassette gene family. NeuroRx 2: 86-98, 2005. 